\title{
Evaluation of Prevalence of Inducible Clindamycin Resistance among Coagulase Negative Staphylococci (CoNS) Isolated from Various Clinical Samples in a Tertiary Care Hospital of North India
}

\author{
Razia Khatoon ${ }^{1}$ and Noor Jahan ${ }^{2 *}$ \\ ${ }^{1}$ Department of Microbiology, Hind Institute of Medical Sciences, Mau, Ataria, \\ Sitapur-261303, India \\ ${ }^{2}$ Department of Microbiology, Integral Institute of Medical Sciences and Research, Integral \\ University, Lucknow-226026, India \\ *Corresponding author
}

\section{A B S T R A C T}

Coagulase-negative Staphylococci (CoNS) have emerged as predominant pathogens in hospital and community acquired infections. Clindamycin is a good therapeutic agent in

\section{Keywords}

Coagulase-negative Staphylococci, D-zone test, Inducible clindamycin resistance, Antibiotic susceptibility, MRCoNS; MSCoNS

\section{Article Info}

Accepted: 08 January 2018 Available Online: 10 February 2018 treatment of skin, soft tissue as well as serious infections caused by both methicillin sensitive and resistant Staphylococci. However, strains with inducible clindamycin resistance often lead to therapeutic failure. Hence, each laboratory should be aware of the local prevalence of this resistance among clinical staphylococcal isolates. Therefore, the present study was done to evaluate the prevalence of inducible clindamycin resistance among CoNS isolates. A total of 152 CoNS isolated from clinical samples were evaluated for antimicrobial susceptibility testing using Kirby Bauer disk diffusion method and simultaneously D-zone test was interpreted by putting clindamycin and erythromycin disks adjacent to each other. Out of $152 \mathrm{CoNS}$ isolates tested, $38.8 \%$ were methicillin resistant (MRCoNS) and 61.2\% were methicillin sensitive (MSCoNS), with $33.6 \%$ hospital acquired strains and $66.4 \%$ community acquired strains. The prevalence of inducible clindamycin resistance was found to be $14.5 \%$, with higher prevalence among MRCoNS $(20.3 \%)$ as compared to MSCoNS (10.8\%), also higher prevalence among community acquired (68.2\%) as compared to hospital acquired strains (31.8\%). All isolates with inducible resistance were $100 \%$ sensitive to vancomycin, linezolid and teicoplanin. To conclude, D-zone test should be performed routinely for appropriate prescription of clindamycin therapy for isolates with true clindamycin sensitivity only.

\section{Introduction}

Coagulase-negative Staphylococci (CoNS), which are the normal skin flora, have emerged as predominant pathogens in nosocomial as well as community acquired infections (Kloos and Bannerman, 1994; Roopa and Biradar,
2015). Risk factors include patients with intravascular catheters or prosthetic devices. These bacteria usually infect immune compromised hosts, such as premature newborns and patients with leukemia or other malignant diseases (Sheikh and Mehdinejad, 2012). CoNS species have been documented 
as a cause of nosocomial bacteremia, infections of wound, urinary tract, central nervous system shunt, endocarditis, surgical site infections, endophthalmitis, peritonitis, bone and joint as well as pediatric and neonatal infections (Tayyar et al., 2015). These infections are not easy to treat because of the risk factors and the multiple drug resistance displayed by these organisms (Asangi et al., 2011).

The increasing prevalence of methicillin resistance among Staphylococci is a therapeutic threat (Novotna et al., 2005). The macrolides, lincosamides (clindamycin) and type B streptogramins $\left(\mathrm{MLS}_{\mathrm{B}}\right)$ are considered to be good alternative therapeutic agents available to address this issue. These agents are chemically distinct but exert similar action by binding to $50 \mathrm{~S}$ ribosomal subunit inhibiting bacterial protein synthesis. Their unrestricted consumption has increased the rate of resistance to these drugs (Delialioglu et al., 2005).

In Staphylococci, resistance to $\mathrm{MLS}_{\mathrm{B}}$ antibiotics is usually caused either by active efflux mechanism encoded by msrA gene, affecting macrolides and type B streptogramins, which results in MS phenotype (resistance to macrolides and group B streptogramins and susceptibility to lincosamides); or by target site modification via $23 \mathrm{~S}$ rRNA methylation encoded by erm genes which confers constitutive or inducible resistance to $\mathrm{MLS}_{\mathrm{B}}$ agents (Fiebelkorn et al., 2003). Strains with constitutive $\mathrm{MLS}_{\mathrm{B}}$ resistance $\left(\mathrm{cMLS}_{\mathrm{B}}\right)$ phenotype show resistance to all $\mathrm{MLS}_{\mathrm{B}}$ drugs without any need to an inducer. In contrast, in inducible $\mathrm{MLS}_{\mathrm{B}}$ resistance (iMLS $\mathrm{B}_{\mathrm{B}}$ ), exposure to a strong methylation inducer (e.g., erythromycin) results in the expression of resistance to lincosamides and streptogramins B (Fiebelkorn et al., 2003). However, it has been demonstrated that spontaneous mutations can transform $\mathrm{iMLS}_{\mathrm{B}}$ phenotype to $\mathrm{cMLS}_{\mathrm{B}}$, without the presence of an inducer (Lewis and Jorgensen, 2005).

In clinical practice, relying just on routine disk diffusion methods lead to misidentification of $\mathrm{iMLS}_{\mathrm{B}}$ phenotype as these appear erythromycin resistant and clindamycin sensitive in vitro when not placed adjacent to each other. This may result in inappropriate institution of clindamycin therapy leading to selection of constitutive erm mutants and consequently treatment failure (Thapa and Sapkota, 2016). On the other hand, considering all erythromycin-resistant strains as clindamycin resistant makes the effect of latter drug underestimate in infections caused by clindamycin susceptible isolates (MS phenotypes) (Aghazadeh et al., 2015). Hence, using an appropriate method like double disk diffusion method (D-zone test) as recommended by Clinical and Laboratory Standards Institute (CLSI, 2015) for determination of $\mathrm{iMLS}_{\mathrm{B}}$ phenotypes would be very informative for better control of CoNS infections.

As reports on inducible clindamycin resistance, especially, among CoNS were scanty from our geographic area, therefore, the present study was undertaken to find out the prevalence of inducible clindamycin resistant CoNS isolated from various clinical samples in our hospital by using D-zone test.

\section{Materials and Methods}

A total of 152 consecutive, non-duplicate strains of CoNS isolated from clinical samples like pus, synovial fluid, blood, sputum and intravenous catheter received in the clinical bacteriology laboratory of department of Microbiology from both inpatients and outpatients attending Hind Institute of Medical Sciences, Mau, Ataria, Sitapur, were included in the study being conducted over a period of 
1 year from August 2015 to July 2016. Other Gram positive bacterial isolates and duplicate CoNS isolates from the same patient were excluded from the study. The study was approved by Institutional Ethics Committee. The clinical isolates were identified as CoNS by performing standard microbiological procedures (Koneman et al., 2006). Antibiotic susceptibility testing was performed on Mueller-Hinton agar (HiMedia Laboratories, Mumbai, India) by Kirby Bauer disk diffusion method as per CLSI guidelines. The antibiotic disks (HiMedia Laboratories, Mumbai, India) used were penicillin (10 units), gentamicin $(10 \mu \mathrm{g})$, amikacin $(30 \mu \mathrm{g})$, doxycycline (30 $\mu \mathrm{g})$, trimethoprim/sulfamethoxazole (1.25/ $23.75 \mu \mathrm{g})$, cefoxitin $(30 \mu \mathrm{g})$, erythromycin $(15 \mu \mathrm{g})$, clindamycin $(2 \mu \mathrm{g})$, ciprofloxacin $(5 \mu \mathrm{g})$, chloramphenicol $(30 \mu \mathrm{g})$, linezolid $(30 \mu \mathrm{g})$ and teicoplanin $(30 \mu \mathrm{g})$ (CLSI, 2015). D-zone test was performed simultaneously by placing erythromycin and clindamycin disks adjacent to each other at a distance of $15 \mathrm{~mm}$ edge to edge (CLSI, 2015). After 18 hours of incubation at $35^{\circ} \mathrm{C}$, blunting of the clindamycin zone of inhibition (D-shaped zone) proximal to the erythromycin disk was considered as positive D-zone test as it indicated an inducible type of resistance or $\mathrm{iMLS}_{\mathrm{B}}$ phenotype and resistance to both erythromycin and clindamycin indicated constitutive resistance or $\mathrm{cMLS}_{\mathrm{B}}$ phenotype (Figure 1 and 2 respectively). Isolates which were resistant to erythromycin and remained sensitive to clindamycin with circular zone of inhibition (no induction) were considered as negative D-zone test and were defined as having the MS phenotype (Figure 3).

Isolates showing resistance to $30 \mu \mathrm{g}$ cefoxitin disk (zone of inhibition $\leq 24 \mathrm{~mm}$ ) were reported as oxacillin resistant or methicillin resistant CoNS (MRCoNS) and those sensitive to $30 \mu \mathrm{g}$ cefoxitin disk (zone of inhibition $\geq$ $25 \mathrm{~mm}$ ) were reported as oxacillin sensitive or methicillin sensitive CoNS (MSCoNS).
Susceptibility of MRCoNS to vancomycin was tested by agar dilution method as per CLSI guidelines. $10 \mu \mathrm{l}$ of $0.5 \mathrm{McF}$ arland bacterial suspensions was spot inoculated on Mueller-Hinton agar plates by using micropipette. The plates were analyzed after 24 hours of incubation at $35^{\circ} \mathrm{C}$. Minimal inhibitory concentration (MIC) of vancomycin of $\leq 4 \mu \mathrm{g} / \mathrm{mL}$ for CoNS was considered as susceptible to vancomycin. Staphylococcus aureus American Type Culture Collection (ATCC) 25923 was used to achieve quality control for antibiotic sensitivity tests (CLSI, 2015).

\section{Statistical analysis}

The collected data were statistically analyzed using SPSS Data Editor Software, Chicago, version 20. The statistical association was evaluated using Chi-square test and $p<0.05$ was taken as statistically significant.

\section{Results and Discussion}

A total of 152 CoNS isolates were tested in our study. As shown in Figure 4, majority of these isolates were derived from pus samples (35.5\%), followed by blood (22.4\%), intravenous catheter $(18.4 \%)$, synovial fluid $(17.1 \%)$ and least from sputum samples (6.6\%). As shown in Table 1, out of 152 CoNS isolates, only $31.6 \%$ were uniformly sensitive to both erythromycin and clindamycin disks, while $68.4 \%$ were erythromycin resistant, with predominantly MS phenotype $(27.6 \%)$, followed by $\mathrm{cMLS}_{\mathrm{B}}$ $(26.3 \%)$ and iMLS $_{\mathrm{B}}$ phenotype $(14.5 \%)$. Amongst 152 CoNS isolates tested, 59 (38.8\%) were methicillin resistant (MRCoNS) and $93(61.2 \%)$ were methicillin sensitive (MSCoNS), with 51 (33.6\%) isolates derived from inpatients (hospital acquired strains) and $101(66.4 \%)$ isolates derived from outpatients (community acquired strains). Amongst MRCoNS, $\mathrm{cMLS}_{\mathrm{B}}$ phenotype predominated 
(49.2\%, 29/59 isolates), followed by iMLS (20.3\%, 12/59 isolates) and MS phenotypes $(18.6 \%, 11 / 59$ isolates). However, the hospital acquired MRCoNS showed $\mathrm{cMLS}_{\mathrm{B}}$ phenotype predominantly (70.9\%) and community acquired MRCoNS showed predominantly MS and $\mathrm{iMLS}_{\mathrm{B}}$ phenotype $(28.6 \%$ each). These findings were found to be statistically significant $(\mathrm{p}=0.006)$. Amongst MSCoNS, MS phenotype predominated $(33.3 \%, 31 / 93$ isolates), followed by $\mathrm{cMLS}_{\mathrm{B}}$ phenotypes $\left(11.8 \%, 11 / 93\right.$ isolates) and $\mathrm{iMLS}_{\mathrm{B}}$ phenotype (10.8\%, 10/93 isolates).

However, the hospital acquired MSCoNS showed predominantly $\mathrm{cMLS}_{\mathrm{B}}$ phenotype (50.0\%) and community acquired MSCoNS showed predominantly MS phenotype (41.1\%). This difference was found to be highly significant statistically $(\mathrm{p}<0.001)$. The overall prevalence of inducible clindamycin resistance (iMLS $S_{B}$ phenotype) amongst the CoNS isolates was found to be $14.5 \%(22 / 152$ isolates), with its prevalence being found more among MRCoNS (20.3\%, 12/59 isolates) as compared to MSCoNS (10.8\%, $10 / 93$ isolates), also its prevalence was more among community acquired strains $(68.2 \%, 15 / 22$ isolates) as compared to hospital acquired strains (31.8\%, 7/22 isolates).

Table 2 depicted that the prevalence of $i M L S_{B}$ phenotypes predominated in isolates recovered from blood (20.6\%, 7/34 isolates), followed by pus $(18.5 \%, 10 / 54$ isolates), synovial fluid (15.4\%, 4/26 isolates) and intravenous catheter $(3.6 \%, 1 / 28$ isolates). None of the isolates recovered from sputum sample showed $\mathrm{iMLS}_{\mathrm{B}}$ phenotype. These findings were found to be statistically significant ( $\mathrm{p}=$ 0.029 ).

Table 3 shows the comparative evaluation of the antibiotic susceptibility of MRCoNS and MSCoNS having inducible clindamycin resistance. It was found that all the isolates with inducible resistance phenotype were $100 \%$ sensitive to linezolid, teicoplanin and vancomycin, followed by sensitivity to amikacin (86.4\%), doxycycline (81.8\%), gentamicin (77.3\%) and chloramphenicol (68.2\%). This finding was statistically significant $(\mathrm{p}=0.041)$. The MRCoNS isolates were more resistant to trimethoprim / sulfamethoxazole and ciprofloxacin as compared to MSCoNS isolates. These differences were found to be statistically significant $(\mathrm{p}=0.035$ and $\mathrm{p}=0.003$ respectively).

In our study, maximum CoNS isolates were derived from pus samples (35.5\%), followed by blood $(22.4 \%)$, intravenous catheter $(18.4 \%)$ and synovial fluid (17.1\%).

This finding is in agreement to another study which also reported maximum isolation of CoNS strains from pus and pus swabs (37.2\%) followed by blood (25.2\%) (Bansal et al., 2012). However, in contrast to our findings studies from Jaipur and Uttarakhand reported maximum isolation of CoNS from blood followed by pus samples (Pal et al., 2010; Juyal et al., 2013).

Our study reported $38.8 \%$ MRCoNS and $61.2 \%$ MSCoNS, which is similar to another study that reported $35.6 \%$ MRCoNS and 64.4\% MSCoNS (Bansal et al., 2012). A study from Uttarakhand also reported higher prevalence of MSCoNS (71.6\%) as compared to MRCoNS (28.4\%) (Juyal et al., 2013). However, the prevalence of MRCoNS in clinical samples has been reported between $55 \%-77 \%$ and even $86 \%$ in intensive care units, from different countries (Piette and Verschraegen, 2009).

Clindamycin is a good therapeutic agent for the treatment of both meticillin-resistant and susceptible staphylococcal infections (Kloos and Bannerman, 1994). 
Table.1 Distribution of CoNS isolates on the basis of their strain type and their susceptibility to cefoxitin and to erythromycin and clindamycin in D-zone test

\begin{tabular}{|c|c|c|c|c|c|c|}
\hline $\begin{array}{l}\text { CoNS isolates, } \\
N=152 \\
(\mathbf{1 0 0 \%})\end{array}$ & Strain type & $\begin{array}{l}\text { Susceptible } \\
\text { phenotype, } \\
\mathrm{N}=48 \\
(31.6 \%)\end{array}$ & $\begin{array}{l}\text { cMLS }_{\mathrm{B}} \\
\text { phenotype, } \\
\mathrm{N}=\mathbf{4 0} \\
(\mathbf{2 6 . 3 \%})\end{array}$ & $\begin{array}{l}\text { MS } \\
\text { phenotype } \\
\text { (Negative D- } \\
\text { zone test), } \\
\text { N=42 }(27.6 \%)\end{array}$ & $\begin{array}{l}\text { iMLS }_{\mathrm{B}} \\
\text { phenotype } \\
\text { (Positive D- } \\
\text { zone test), } \\
\mathrm{N}=22 \\
(\mathbf{1 4 . 5 \% )}\end{array}$ & $\begin{array}{l}\text { Chi-Square } \\
\left(\chi^{2}\right) \& * \text { v value }\end{array}$ \\
\hline \multirow[t]{2}{*}{$\begin{array}{l}\text { MRCoNS } \\
\mathrm{N}=59(38.8 \%)\end{array}$} & $\begin{array}{l}\text { Hospital } \\
\text { acquired, } \mathrm{N}=31 \\
(52.5 \%)\end{array}$ & $2(6.5 \%)$ & $22(70.9 \%)$ & $3(9.7 \%)$ & $4(12.9 \%)$ & \multirow[t]{2}{*}{$\begin{array}{l}\chi^{2}=12.530 p= \\
0.006\end{array}$} \\
\hline & $\begin{array}{l}\text { Community } \\
\text { acquired, } N=28 \\
(47.5 \%)\end{array}$ & $5(17.8 \%)$ & $7(25.0 \%)$ & $8(28.6 \%)$ & $8(28.6 \%)$ & \\
\hline \multirow[t]{2}{*}{$\begin{array}{l}\text { MSCoNS } \\
\mathrm{N}=93(61.2 \%)\end{array}$} & $\begin{array}{l}\text { Hospital } \\
\text { acquired, } \mathrm{N}=20 \\
(21.5 \%)\end{array}$ & $6(30.0 \%)$ & $10(50.0 \%)$ & $1(5.0 \%)$ & $3(15.0 \%)$ & \multirow[t]{2}{*}{$\begin{array}{l}\chi^{2}=39.099 p< \\
0.001\end{array}$} \\
\hline & $\begin{array}{l}\text { Community } \\
\text { acquired, } N=73 \\
(78.5 \%)\end{array}$ & $35(47.9 \%)$ & $1(1.4 \%)$ & $30(41.1 \%)$ & $7(9.6 \%)$ & \\
\hline
\end{tabular}

CoNS = coagulase negative Staphylococci; $\mathbf{N}=$ Number of CoNS isolates; MRCoNS = Methicillin resistant CoNS i.e. isolates resistant to cefoxitin; MSCoNS = Methicillin sensitive CoNS i.e. isolates sensitive to cefoxitin; Hospital acquired strains = isolates recovered from inpatients; Community acquired strains = isolates recovered from outpatients; Susceptible phenotype = isolates sensitive to both erythromycin and clindamycin; cMLS $_{\mathrm{B}}$ phenotype = isolates with constitutive resistance to clindamycin; MS phenotype = isolates with susceptibility to clindamycin and negative D-zone test; iMLS $_{\mathrm{B}}$ phenotype = isolates with inducible resistance to clindamycin and positive D-zone test. *p value $<0.05$ was considered as statistically significant.

Table.2 Distribution of CoNS isolates with inducible clindamycin resistance among clinical samples tested

\begin{tabular}{|c|c|c|c|c|}
\hline \multirow{2}{*}{$\begin{array}{l}\text { Samples } \\
\text { tested }\end{array}$} & \multicolumn{3}{|c|}{ iMLS $_{B}$ phenotype } & \multirow{2}{*}{$\begin{array}{l}\text { Chi-Square }\left(\chi^{2}\right) \\
\& * \text { p value }\end{array}$} \\
\hline & $\begin{array}{l}\text { Present in } \\
\text { MRCoNS, } \\
\mathrm{N}=12(7.9 \%)\end{array}$ & $\begin{array}{l}\text { Present in } \\
\text { MSCoNS, } \\
\mathrm{N}=10(6.6 \%)\end{array}$ & $\begin{array}{l}\text { Not Present**, } \\
\mathrm{N}=130(85.5 \%)\end{array}$ & \\
\hline Pus & $9(16.7 \%)$ & $1(1.8 \%)$ & $44(81.5 \%)$ & \multirow[t]{5}{*}{$\chi^{2}=16.807, p=0.032$} \\
\hline $\begin{array}{l}\text { Synovial } \\
\text { fluid }\end{array}$ & $1(3.8 \%)$ & $2(7.7 \%)$ & $23(88.5 \%)$ & \\
\hline Blood & $2(5.9 \%)$ & $5(14.7 \%)$ & $27(79.4 \%)$ & \\
\hline Sputum & $0(0 \%)$ & $0(0 \%)$ & $10(100 \%)$ & \\
\hline $\begin{array}{l}\text { Intravenous } \\
\text { catheter }\end{array}$ & $0(0 \%)$ & $1(3.6 \%)$ & $27(96.4 \%)$ & \\
\hline \multicolumn{5}{|c|}{$\begin{array}{l}\text { CoNS = Coagulase negative Staphylococci. } \text { iMLS }_{\mathrm{B}} \text { phenotype }=\text { isolates with inducible } \\
\text { clindamycin resistance. } \mathbf{N}=\text { Number of } \mathrm{CoNS} \text { isolates. MRCoNS = Methicillin resistant } \\
\text { CoNS; MSCoNS = Methicillin sensitive CoNS. *p value }<0.05 \text { was considered as } \\
\text { statistically significant. **signifies presence of isolates having susceptible, constitutive } \\
\text { resistance and MS phenotypes. }\end{array}$} \\
\hline
\end{tabular}


Table.3 Comparison of antibiotic susceptibility pattern among MRCoNS and MSCoNS isolates having inducible clindamycin resistance $(\mathrm{N}=22)$

\begin{tabular}{|c|c|c|c|c|}
\hline \multicolumn{2}{|l|}{ Antibiotics tested } & $\begin{array}{l}\text { MRCoNS, N = } \\
12(100 \%)\end{array}$ & $\begin{array}{l}\text { MSCoNS, } N= \\
10(100 \%)\end{array}$ & $\begin{array}{l}\text { Chi-Square }\left(\chi^{2}\right) \\
\& * \text { p value }\end{array}$ \\
\hline \multirow[t]{2}{*}{ Penicillin } & Resistant & $12(100 \%)$ & $7(70.0 \%)$ & \multirow{2}{*}{$\chi^{2}=4.168, p=0.041$} \\
\hline & Sensitive & $0(0 \%)$ & $3(30.0 \%)$ & \\
\hline \multirow[t]{2}{*}{ Gentamicin } & Resistant & $3(25.0 \%)$ & $2(20.0 \%)$ & \multirow[t]{2}{*}{$\chi^{2}=0.078, p=0.781$} \\
\hline & Sensitive & $9(75.0 \%)$ & $8(80.0 \%)$ & \\
\hline \multirow[t]{2}{*}{ Amikacin } & Resistant & $2(16.7 \%)$ & $1(10.0 \%)$ & \multirow[t]{2}{*}{$\chi^{2}=0.206, p=0.650$} \\
\hline & Sensitive & $10(83.3 \%)$ & $9(90.0 \%)$ & \\
\hline \multirow[t]{2}{*}{ Doxycycline } & Resistant & $2(16.7 \%)$ & $2(20.0 \%)$ & \multirow[t]{2}{*}{$\chi^{2}=0.041, p=0.840$} \\
\hline & Sensitive & $10(83.3 \%)$ & $8(80.0 \%)$ & \\
\hline \multirow{2}{*}{$\begin{array}{l}\text { Trimethoprim- } \\
\text { sulfamethoxazole }\end{array}$} & Resistant & $10(83.3 \%)$ & $4(40.0 \%)$ & \multirow[t]{2}{*}{$\chi^{2}=4.426, p=0.035$} \\
\hline & Sensitive & $2(16.7) \%$ & $6(60.0 \%)$ & \\
\hline \multirow[t]{2}{*}{ Cefoxitin } & Resistant & $12(100 \%)$ & $0(0 \%)$ & \multirow[t]{2}{*}{$\chi^{2}=22.000, p<0.001$} \\
\hline & Sensitive & $0(0 \%)$ & $10(100 \%)$ & \\
\hline \multirow[t]{2}{*}{ Ciprofloxacin } & Resistant & $11(91.7 \%)$ & $3(30.0 \%)$ & \multirow{2}{*}{$\chi^{2}=8.964, p=0.003$} \\
\hline & Sensitive & $1(8.3) \%$ & $7(70.0 \%)$ & \\
\hline \multirow[t]{2}{*}{ Chloramphenicol } & Resistant & $5(41.7 \%)$ & $2(20.0 \%)$ & \multirow[t]{2}{*}{$\chi^{2}=1.180, p=0.277$} \\
\hline & Sensitive & $7(58.3 \%)$ & $8(80.0 \%)$ & \\
\hline \multirow[t]{2}{*}{ Vancomycin } & Resistant & $0(0 \%)$ & $0(0 \%)$ & \multirow[t]{2}{*}{ NA } \\
\hline & Sensitive & $12(100 \%)$ & $10(100 \%)$ & \\
\hline \multirow[t]{2}{*}{ Linezolid } & Resistant & $0(0 \%)$ & $0(0 \%)$ & \multirow[t]{2}{*}{ NA } \\
\hline & Sensitive & $12(100 \%)$ & $10(100 \%)$ & \\
\hline \multirow[t]{2}{*}{ Teicoplanin } & Resistant & $0(0 \%)$ & $0(0 \%)$ & \multirow[t]{2}{*}{ NA } \\
\hline & Sensitive & $12(100 \%)$ & $10(100 \%)$ & \\
\hline
\end{tabular}

Fig.1 Isolate with inducible clindamycin resistance or positive D-zone test with blunting (Dshaped) of clindamycin zone of inhibition proximal to the erythromycin disk

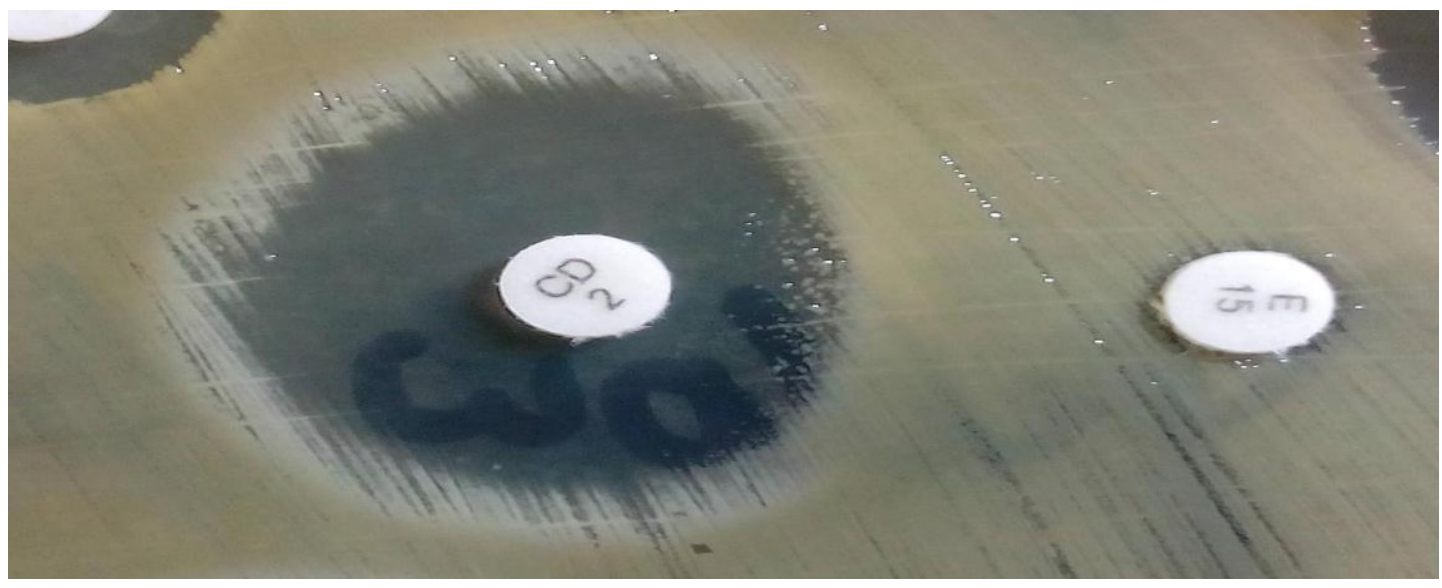


Fig.2 Isolate with constitutive resistance to both erythromycin and clindamycin disks

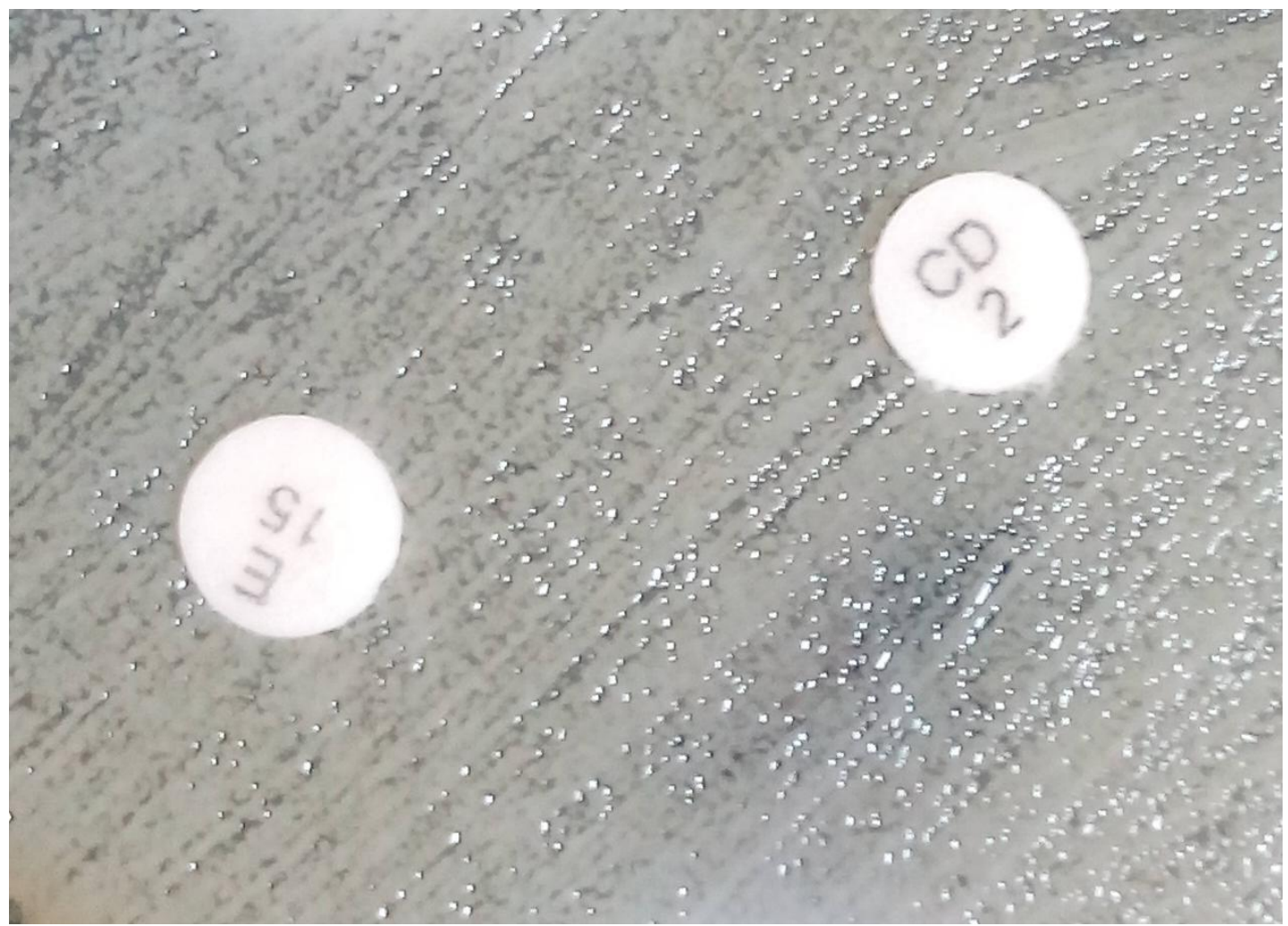

Fig.3 MS phenotype or negative D-zone test with resistance to erythromycin and sensitivity to clindamycin (circular zone of inhibition or no induction)

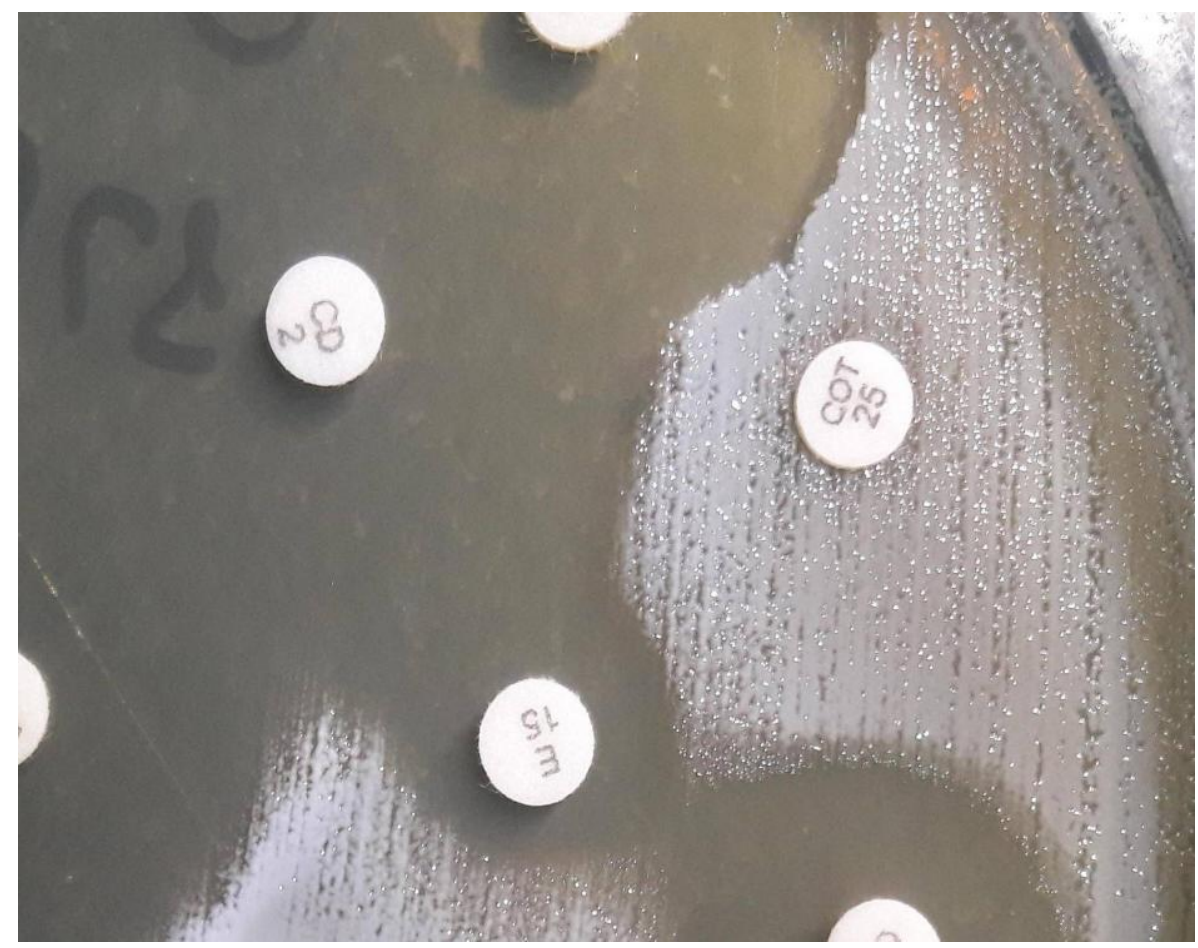


Fig.4 Distribution of CoNS isolates among clinical samples tested
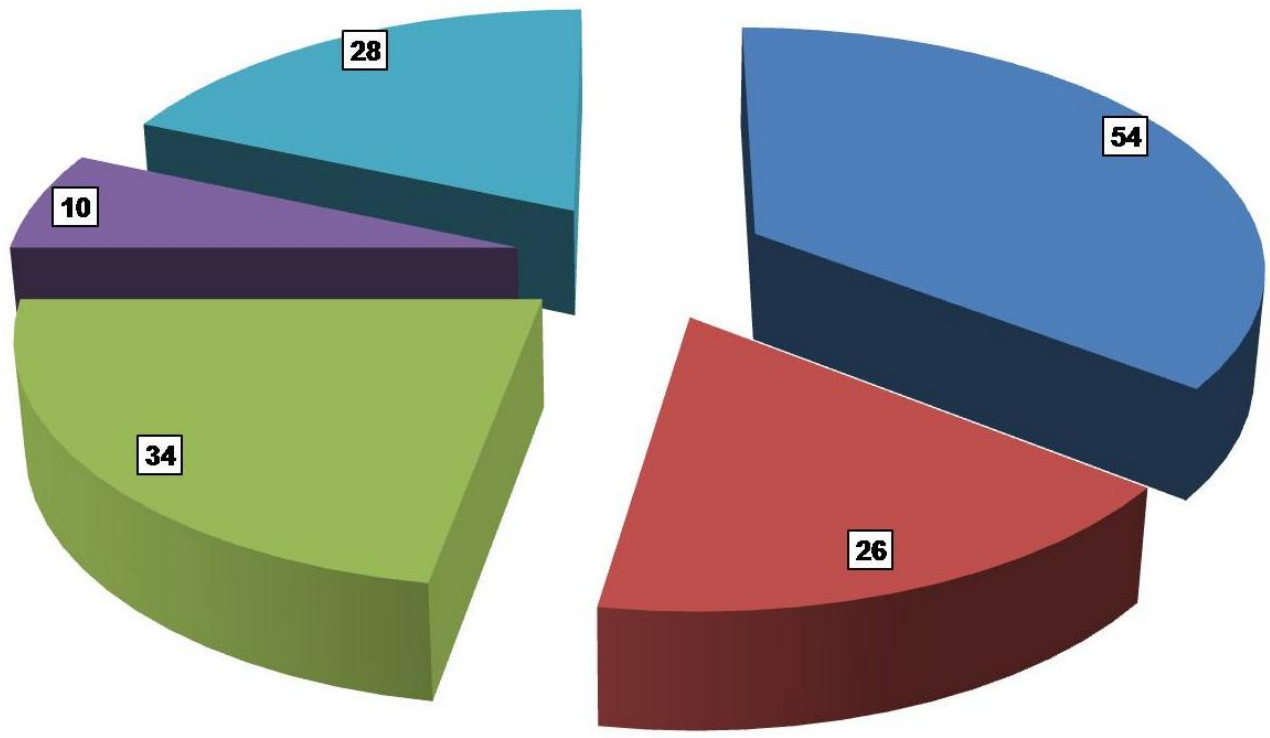

- Pus = Synovial fluid

Blood Sputum

Intravenous catheter

However, resistance can develop in staphylococcal isolates with inducible phenotypes due to selection of constitutively resistant mutants both in vitro and in vivo during clindamycin therapy (Rao, 2000). Therefore, such isolates should be identified prior to subscription of clindamycin. This is where the D-test becomes significant. On putting D-zone test we found that amongst 59 MRCoNS, cMLS $\mathrm{S}_{\mathrm{B}}$ phenotype predominated (49.2\%), followed by iMLS $(20.3 \%)$ and MS phenotypes (18.6\%), whereas, amongst 93 MSCoNS, MS phenotype predominated (33.3\%), followed by $\mathrm{cMLS}_{\mathrm{B}}$ phenotypes $(11.8 \%)$ and iMLS $_{\mathrm{B}}$ phenotype (10.8\%). Another study reported that among 89 MRCoNS isolates, $\mathrm{cMLS}_{\mathrm{B}}$ resistance predominated $(51.7 \%)$, followed by $\mathrm{iMLS}_{\mathrm{B}}$ resistance and the MS phenotype (25.8\% and $12.4 \%$ respectively), whereas, among 161 MSCoNS isolates, MS phenotype was predominant $(27.3 \%)$, followed by $\mathrm{iMLS}_{\mathrm{B}}$ $(13.7 \%)$ and $\mathrm{cMLS}_{\mathrm{B}} \quad(11.8 \%)$ resistance respectively (Bansal et al., 2012). This finding was in partial agreement to our report. A study from Rajasthan reported that among 153
MRCoNS, iMLS $S_{B}$ phenotype predominated (21.56\%), followed by MS (19.60\%) and $\mathrm{cMLS}_{\mathrm{B}}$ phenotypes (13.07\%) (Supriyarajvi et $a l ., 2015)$. This finding was in contrast to our study. However, their findings of MSCoNS were in agreement to that of our study as they reported that among 133 MSCoNS, MS phenotype predominated (26.31\%), followed by $\mathrm{CMLS}_{\mathrm{B}}(15.03 \%)$ and $\mathrm{iMLS}_{\mathrm{B}}$ phenotype $(11.21 \%)$. Another contrasting finding was reported by a study from Telangana which showed that among 50 MRCoNS isolates, MS phenotype predominated (34.0\%), followed by $\mathrm{cMLS}_{\mathrm{B}}(22.0 \%)$ and iMLS $\mathrm{B}$ phenotype (18.0\%) (Zachariah et al., 2016).

In our study the overall prevalence of inducible clindamycin resistance among CoNS isolates was $14.5 \%$. A study from Rajasthan reported prevalence of $\mathrm{iMLS}_{\mathrm{B}}$ resistance phenotypes amongst CoNS isolates to be $16.8 \%$ (48/286 isolates) (Supriyarajvi et al., 2015). Study from Uttarakhand reported prevalence of $\mathrm{iMLS}_{\mathrm{B}}$ resistance among CoNS isolates to be $19.4 \%$ (26/134 isolates) (Juyal et al., 2013). These variations in the prevalence of inducible 
clindamycin resistance in different geographical areas could be due to differences in bacterial susceptibility and varying antimicrobial subscribing patterns of physicians (Bansal et al., 2012).

In our study, we found higher prevalence of inducible clindamycin resistance $\left(\mathrm{iMLS}_{\mathrm{B}}\right.$ phenotype) among community acquired strains (68.2\%) as compared to hospital acquired strains $(31.8 \%)$. Probable reason behind this finding could be that clindamycin being an oral drug is frequently prescribed by physicians in outdoor clinical settings leading to increased incidence of $\mathrm{iMLS}_{\mathrm{B}}$ resistance phenotype among community acquired strains of CoNS.

In the present study we found that all the CoNS isolates with inducible clindamycin resistance were $100 \%$ sensitive to vancomycin, linezolid and teicoplanin, followed by sensitivity to amikacin (86.4\%), doxycycline (81.8\%), gentamicin $(77.3 \%)$ and chloramphenicol $(68.2 \%)$, with least sensitivity to penicillin (13.6\%). Similarly a study from Jaipur also reported that isolates with $\mathrm{iMLS}_{\mathrm{B}}$ phenotype were $100 \%$ sensitive to vancomycin and linezolid, followed by sensitivity to ciprofloxacin (78.78\%), doxycycline and piperacillin / tazobactam (69.56\% each) (Pal et al., 2010).

Clindamycin has long been an attractive option in the treatment of skin and soft tissue infections as well as serious infections because of its efficacy against both methicillin sensitive and resistant Staphylococci. However, treatment failure may result when clindamycin is used for therapy of staphylococcal strains that exhibit inducible resistance. Therefore, it is important for all laboratories to be aware of the local prevalence of inducible clindamycin resistant Staphylococci as the incidence is highly variable with regard to geographical area. The D-zone test is an easy, sensitive, and reliable means for detection of such strains in clinical laboratory settings and should be performed routinely for proper guidance of clinicians in prescription of clindamycin for treatment of patients with true clindamycin susceptible strains and its avoidance when inducible resistance is detected thus preventing treatment failure.

\section{References}

Aghazadeh M, Ghotaslou R, Rezaee MA, Moshafi MH, Hojabri Z, Saffari F. Determination of the antimicrobial resistance profile and inducible clindamycin resistance of coagulase negative Staphylococci in pediatric patients: the first report from Iran. World J Pediatr 2015; 11:250-254.

Al Tayyar IA, Al Zoubi MS, Hussein E, Khudairat S, Sarosiekf K. Prevalence and antimicrobial susceptibility pattern of coagulase negative Staphylococci (CoNS) isolated from clinical specimens in Northern of Jordan. Iranian J Microbiol 2015; 7:294-301.

Asangi SY, Mariraj J, Sathyanarayan MS, Nagabhushan R. Speciation of clinically significant Coagulase Negative Staphylococci and their antibiotic resistant pattern in a tertiary care hospital. Int J Biol Med Res 2011; 2:735-739.

Bansal N, Chaudhary U, Gupta V. Prevalence of inducible clindamycin resistance in clinical isolates of coagulase negative Staphylococci at a tertiary care hospital. Ann Trop Med Public Health 2012; 5:427-430.

Clinical and Laboratory Standards Institute (CLSI). Performance standards for antimicrobial susceptibility testing; Twenty-fifth informational supplement. CLSI document M100-S25. CLSI, Wayne, Pennsylvania, USA, 2015.

Delialioglu N, Aslan G, Ozturk C, Baki V, Sen $\mathrm{S}$, Emekdas G. Inducible clindamycin resistance in Staphylococci isolated from clinical samples. Jpn J Infect Dis 2005; 58:104-106.

Fiebelkorn KR, Crawford SA, McElmeel ML, Jorgensen JH. Practical disk diffusion method for detection of inducible clindamycin resistance in Staphylococcus 
aureus and coagulase negative Staphylococci. J Clin Microbiol 2003; 41:4740-4744.

Juyal D, Shamanth AS, Pal S, Sharma MK, Prakash R, Sharma N. The prevalence of inducible clindamycin resistance among Staphylococci in a tertiary care hospital A study from Garhwal Hills of Uttarakhand, India. J Clin Diag Res 2013; 7:61-65.

Kloos WE, Bannerman TL. Update on clinical significance of coagulase-negative Staphylococci. Clin Microbiol Rev 1994; 7:117-140.

Koneman WE, Allen SD, Janda WM, Schreckenberger PC, Winn Jr. WC, Procop G and Woods G. The Gram positive cocci: Part I: Staphylococci and related organisms. In Koneman's Color Atlas and Textbook of Diagnostic Microbiology, $6^{\text {th }}$ Edition, Lippincott Williams \& Wilkins, Philadelphia, New York, 2006, pp 623-671.

Lewis JS 2nd, Jorgensen JH. Inducible clindamycin resistance in Staphylococci: should clinicians and microbiologists be concerned? Clin Infect Dis 2005; 40:280285.

Novotna G, Adamkova V, Janata J, Melter O, Spizek J. Prevalence of resistance mechanisms against macrolides and lincosamides in methicillin-resistant coagulase-negative Staphylococci in the Czech Republic and occurrence of an undefined mechanism of resistance to lincosamides. Antimicrob Agents Chemother 2005; 49:3586-3589.

Pal N, Sharma B, Sharma R, Vyas L. Detection of inducible clindamycin resistance among Staphylococcal isolates from different clinical specimens in western India. J Postgrad Med 2010; 56:182-185.

Piette A, Verschraegen G. Role of coagulasenegative Staphylococci in human disease. Vet Microbiol 2009; 134:45-54.

Rao GG. Should clindamycin be used in treatment of patients with infections caused by erythromycin-resistant Staphylococci? J Antimicrob Chemother 2000; 45:715.

Roopa C, Biradar S. Incidence and speciation of coagulase negative staphylococcus isolates from clinically relevant specimens with their antibiotic susceptibility patterns. Int J Curr Microbiol App Sci 2015; 4:975-980.

Sheikh AF, Mehdinejad M. Identification and determination of coagulase negative Staphylococci species and antimicrobial susceptibility pattern of isolates from clinical specimens. Afr J Microbiol Res 2012; 6:1669-1674.

Supriyarajvi, Gupta A, Tina G, Sharma BP. Detection of inducible clindamycin resistance among Staphylococcal isolates from various clinical specimens in a tertiary care institute in North West region of Rajasthan, India. Int $\mathbf{J}$ Curr Microbiol App Sci 2015; 4:741-749.

Thapa S, Sapkota LB. Prevalence of inducible clindamycin resistance in erythromycin resistant clinical isolates of Staphylococcus aureus and CONS at tertiary care hospital. J Col Med Sci Nepal 2016; 12:83-88.

Zachariah R, Basireddy S, Kabra V, Singh M, Ali S, Sardar A. Phenotypic characterization of macrolide and lincosamide resistance patterns in clinical isolates of Staphylococci. JNTR Univ Health Sci 2016; 5:187-191.

\section{How to cite this article:}

Razia Khatoon and Noor Jahan. 2018. Evaluation of Prevalence of Inducible Clindamycin Resistance among Coagulase Negative Staphylococci (CoNS) Isolated from Various Clinical Samples in a Tertiary Care Hospital of North India. Int.J.Curr.Microbiol.App.Sci. 7(02): 513-522. doi: https://doi.org/10.20546/ijcmas.2018.702.065 